\title{
Is management of risk sharing by banks a cause for bank runs?
}

\author{
H. Abraham* \\ School of Economics, University of Cape Town \\ Private Bag, Rondebosch 7701, Republic of South Africa \\ haim.abraham@uct.ac.za
}

Received November 2009

\begin{abstract}
A bank, acting as a central planner under aggregate full certainty, optimizes liquidity allocation by sharing risk between discrete number of depositors. This paper demonstrates the following. (a) It is sufficient to rule out a bank run if all depositors inform the bank their types, patient or impatient, in advance, in a noncommittal manner. There cannot be a bank run because depositors' strategic behaviour induces the bank to act as a central planner under aggregate full certainty. (b) The impossibility of a bank run is consistent with the price mechanism in partial equilibrium; but it may be inconsistent with the price mechanism in general disequilibrium. (c) The paper concludes that the management of risk sharing by banks is not a cause for bank runs.
\end{abstract}

*To whom all correspondence should be addressed.

\section{Introduction}

The issue of bank runs is addressed in the literature from two polar points of view. The one view is Diamond and Dybvig's (1983, henceforth DD); according to which there is a continuum of depositors and the bank acts as their central planer. Depositors act in an uncertain environment. Uncertainty is due to private information that is unknown presently and reaches each depositor only in the future. The law of large numbers ensures that the bank can act under aggregate full certainty. The other view, due to Green and Lin, (2000, henceforth GL), is similar to DD with the proviso that there is a discrete number of depositors. Because the number of depositors is discrete, aggregate uncertainty may not be removed by a bank that acts as a central planner.

It is known that according to the first view there exist two equilibria: a 'good' equilibrium where aggregate risk sharing benefits each depositor, and a 'bad' equilibrium where a run on the bank takes place. Note that despite its existence, a 'good' equilibrium may be inadmissible. It is also known that in the other view no run on the bank is possible. The impossibility of bank run is achieved under the somewhat unrealistic condition that each depositor approaching the bank for the possibility of withdrawing his deposit knows his place in the queue of all depositors approaching the bank for the same purpose.

This paper concentrates on the view that the number of depositors is discrete while the latter condition that each depositor knows his place in the queue is relaxed. Instead, the realistic assumption that each depositor knows his preference for a type, whether patient or impatient, is maintained at the time he makes his deposit in the bank. Each depositor, however, is aware that he might change his preferred type depending on other depositors' revealed behaviour in the future concerning the withdrawal of their deposits. Hence, although each depositor knows his type initially, he is uncertain whether he will keep his type unchanged in the future. At the time each depositor makes his deposit in the bank he informs the bank his type in a noncommittal manner (i.e., in 'cheap talk', e.g., Farrell \& Rabin (1996)). Being aware that the message of each depositor concerning his type is noncommittal, the bank, in turn, draws a contract with each depositor stating that the depositor is allowed to withdraw his deposit either in the near future or in the remote future. Obviously, the return to a deposit depends on its duration.

It will be demonstrated in this paper that the above scenario ensures that no depositor, in a group of discrete number of depositors, will change in the future his presently preferred type. That is, despite the noncommittal message of each depositor to the bank, lying for strategic advantage is not beneficial to any depositor. Since this is known to everyone, the bank, as a central planner, acts from the beginning under aggregate full certainty. Thus, a similar 'good' equilibrium as in DD is achieved while the number of depositors is discrete. Unlike, however, the possibility of a 'bad' equilibrium beside the 'good' equilibrium in DD, here the possibility of a 'bad' equilibrium of bank run is ruled out.

Furthermore, this paper demonstrates that banks in a partial equilibrium framework facilitate the existence of efficient prices. Hence, the operation of the price mechanism is consistent with the existence of a 'good' equilibrium and is inconsistent with the existence of a 'bad' equilibrium. That is, the partial equilibrium framework cannot explain episodes of bank runs. The inclusion of price uncertainty in partial equilibrium still leaves episodes of bank runs unexplained. Since a bank run is a reality and since a partial 
equilibrium framework cannot explain episodes of bank runs, this paper argues that bank runs should be analysed by the price mechanism in a framework of general disequilibrium.

The rest of the paper is structured as follows. First, the framework for discussion is presented. Then, a distinction between two polar cases is drawn, banks with a continuum of depositors and banks with a discrete number of depositors. The paper presents a scenario under which the bank's operation with a discrete number of depositors maintains a 'good' equilibrium similar to that in DD. The paper concludes by showing that the impossibility of a bank run is consistent with the price mechanism in partial equilibrium analysis and may be inconsistent with general disequilibrium analysis. Thus, the mechanism of adjusting disequilibrium prices may be a trigger for bank runs. It is also argued that introducing price uncertainty does not affect the above conclusion that bank runs are impossible in a partial equilibrium setting. The paper suggests that the management of risk sharing by banks is not a cause for bank runs.

\section{Basic framework for discussion}

Consider a bank as an organization set voluntarily by a group of depositors. The bank operates in a competitive environment according to certain binding rules. The objective of the bank is to maximize depositors' welfare. The time profile is open ended with a replica of two periods: near-future, $t=1$ and remote-future, $t=2$. Every period is an interval of time $[0, \mathrm{~T}], \mathrm{T}>0$, where 0 and $\mathrm{T}$ are, respectively, the beginning and end of each period.

$$
\tau=0 \underbrace{---------}_{\mathrm{t}=1} \begin{aligned}
& \tau=0 \overbrace{-----------}^{\mathrm{t}=2} \tau=\mathrm{T} \\
& \tau=\mathrm{T}
\end{aligned}
$$

Each depositor enters the economy with an endowment of 1 unit of a single good which is immediately deposited in a bank. The single good acts in period 1 as a unit of account. Depositors have no endowments in the second period.

The bank can invest the depositors' endowments in two schemes with the following returns. Scheme 1: the endowment of 1 unit is kept in the bank till the end of the first period, it returns $r=1$ units, in this case the asset is liquid. Scheme 2: the endowment of 1 unit is kept in the bank till the end of period 2, it returns $\mathrm{R}>1$ units, in this case the asset is illiquid. Furthermore, an illiquid asset may be terminated prematurely at the end of the first period with a return of 1 unit. Hence, the return of an illiquid asset dominates the return of a liquid asset. Consequently, initially, at the beginning of period 1, the bank will consider all deposits as long term deposits liquidated at the end of period 2 and if need be some deposits will be liquidated at the end of the first period.

In $\mathrm{DD}$ and GL depositors find out their types, whether patient or impatient, at the end of period 1 after receiving a private signal. This seems an unrealistic observation. Instead, in this paper it is maintained that at the beginning of period 1 each depositor tells the bank in a noncommittal manner his preferred type. The depositor is impatient if he withdraws his deposit from the bank at the end of period 1 , and he is patient if he withdraws his deposit from the bank at the end of period 2. Despite this, at the beginning of period 1 when the bank receives the deposits, it draws a contract with each depositor according to which the depositor is allowed to withdraw his deposit either at the end of period 1 or at the end of period 2 irrespective of the depositor's declared preferred type. Thus, the bank and each depositor consider each declared depositor's preferred type as a 'cheap talk', i.e., not binding to each party of the contract. Each depositor can change his mind concerning the duration of his deposit if he deems such an act favourable to him while taking into consideration other depositors' acts. The freedom of each depositor to withdraw his deposit at the end of the first period or at the end of the second period renders depositors' types potentially uncertain. (It will be shown later that 'potential uncertainty' is ineffective in this setting.) The return on each deposit depends on its duration as is stated above.

The only source of potential uncertainty is each depositor's type. This uncertainty prevails only in period 1 , because at the end of period 1 each depositor's type becomes fully known: the impatient depositors withdraw their deposits and the rest are patient depositors. Each depositor enters the economy with a utility function $\mathrm{u}\left(\mathrm{c}_{1}, \mathrm{c}_{2}\right)$ where $\mathrm{c}_{1}$ and $\mathrm{c}_{2}$ are consumptions in period 1 and in period 2 respectively. This function ${ }^{1}$ maintains the expected utility form $\wp \mathrm{u}\left(\mathrm{c}_{1}\right)+(1-\wp) \mathrm{u}\left(\mathrm{c}_{2}\right)$ where $\wp$ and $1-\wp$ are the respective probabilities that a depositor is impatient or patient. After the resolution of uncertainty the impatient depositor's utility is $\mathrm{u}\left(\mathrm{c}_{1}\right)$, he values only near-future consumption; and the patient depositor's utility is $u\left(c_{2}\right)$, he values only remotefuture consumption.

\section{Continuum of depositors}

A bank as a central planner need not know who is a patient and who is an impatient depositor. It only needs to know the proportion of patient versus impatient depositors. Accordingly, DD assume a continuum of depositors where a proportion $\wp$ of depositors are impatient and $1-\wp$ are patient. Because of the law of large numbers, the proportions $\wp$ and $1-\wp$ are also the respective probabilities of impatient and patient depositors. In light of this, and irrespective of any strategic reasoning, the bank acts from the beginning of period 1 under conditions of aggregate full certainty despite the uncertainty that each depositor faces prior to the end of period 1 . This enables the bank to draw a contract with each depositor according to which the bank allows each depositor to withdraw his deposit either at the end of period 1 (with a return $r=1$ ) or at the end of period 2 (with a return $\mathrm{R}>1$ ). Note that because of the continuum of depositors, the only information that is relevant to the bank's operation is the

\footnotetext{
${ }^{1}$ The utility function $\mathrm{u}\left(\mathrm{c}_{1}, \mathrm{c}_{2}\right)$ is concave, monotonically increasing in $\mathrm{c}_{1}, \mathrm{c}_{2}$ and satisfies $\mathrm{u}^{\prime}(0)=\infty, \mathrm{u}^{\prime}(\infty)=0$. It is also assumed that the relative risk aversion coefficient $\mathrm{cu}^{\prime \prime}(\mathrm{c}) / \mathrm{u}^{\prime}(\mathrm{c})>1$ everywhere.
} 
probabilities $\wp$ and $1-\wp$ of impatient and patient depositors which the bank knows in advance before the depositors approach the bank. The message that each depositor conveys to the bank regarding his type has no bearing on the bank's operation.

The objective of the bank is to maximize $\wp \mathrm{u}\left(\mathrm{c}_{1}\right)+(1-\wp) \mathrm{u}\left(\mathrm{c}_{2}\right)$ subject to the two constraints, (1) $\wp \mathrm{C}_{1}=\mathrm{L}$ and (2) $(1-\wp) \mathrm{C}_{2}=\mathrm{R}(1-\wp)$, where $\mathrm{L}$ is the fraction of the asset liquidated at the end of period 1 . This maximization method is a central planning of returns under aggregate full certainty where the bank pools all deposits in order to maximize total welfare of society (see Tirole 2006:454-456)). This maximization method has potentially two equilibria, (a) and (b) below,

(a) either, there exist $c_{1}$ and $c_{2}$ such that,

$\mathrm{u}^{\prime}\left(\mathrm{c}_{1}^{*}\right) / \mathrm{u}^{\prime}\left(\mathrm{c}_{2}^{*}\right)=\mathrm{R}$

in which case, $1<\mathrm{c}_{1}^{*}<\mathrm{c}_{2}^{*}<\mathrm{R}$

(b) or, there exists $c_{1}^{* *}$ for which,

$c_{1}^{* *}=\left\{\begin{array}{llr}c_{1}^{*} & \text { for } & \pi(>\wp<1) \\ 0 & \text { for } & 1-\pi\end{array}\right.$

where $\pi$ is a posterior probability of impatient depositors. Part (a) is labelled a 'good' equilibrium where the marginal condition of utility maximization is satisfied. Furthermore, this equilibrium maintains $1<\mathrm{c}_{1}^{\bullet}<\mathrm{c}_{2}^{*}<\mathrm{R}$ because the relative risk aversion coefficient (footnote 1 ) is greater than 1. Beside (a), a different equilibrium exists, as is stated in part (b). This is labelled a 'bad' equilibrium. A proportion of depositors $\pi-\wp>0$ run on the bank and if this proportion is big enough the bank will run out of liquidity.

Parts (a) and (b) are two conflicting equilibria that result from the same maximization problem of central planning (see Abraham, 2008). At any time before the end of period 1 , both parts seem possible and only in a hind sight (ex post) one of them will exist. Nevertheless, the observation that the two equilibria seem possible suggests that, ex post, the resulting equilibrium depends on the psychology of depositors. This observation contradicts the mathematically objective rule of the minimax criterion that a depositor, who is driven only by logic, utilizes. But if the minimax principle is overridden by an alternative criterion, then the methodology of the alternative criterion must bring some information into the analysis (see Raiffa, 1968:289-295). This is impossible in DD. The bank, acting as a central planner, relies solely on the formal rule of large numbers to conduct its operation.

In light of the above, one can conclude that neither the bank nor any depositors regard any messages (through 'cheap talk') as credible. Therefore no depositor regards such messages as self-committing. This leaves the minimax principle as the only criterion for decision making. That is, paradoxically, from the beginning of period 1 it is common knowledge that the 'good' equilibrium that relies on the psychology of depositors is ruled out.

\section{Discrete number of depositors}

Based on the above it is apparent that the design of an environment of aggregate full certainty under central planning should be a consequence of strategic behaviour of depositors; otherwise, a paradoxical outcome will emerge as in the DD's design. Accordingly, the GL's design of a bank as a club-like arrangement with a discrete number of depositors is utilized here. In the GL's design, when depositors queue to withdraw their deposits from the bank, it is assumed that each one knows his place in the queue. Unlike the DD's design, a bank in GL operates under conditions of aggregate uncertainty because the law of large numbers no longer holds when the number of depositors is discrete.

In this paper the interaction of the bank with its depositors ensures that it operates under conditions of aggregate full certainty. This is achieved by removing the assumption that depositors receive private signals one period after depositing their 1 unit endowment in the bank. Instead, a more realistic assumption is maintained here; namely, depositors engage in a 'cheap talk' with the bank, according to which, at the beginning of period 1 , each depositor informs the bank his preferred type in a noncommittal manner. The bank takes this information as credible (it will be argued in the sequel that in a hind sight the bank's treatment of this information as credible is correct) and acts upon it. Susequently, the bank conducts a similar constrained maximization under aggregate full certainty as in DD, while case (b) of 'bad' equilibrium is ruled out.

\section{Discussion}

At the beginning of period 1 each depositor informs the bank his preferred type. It will now be argued that this information can never be untruthful when the number of depositors is discrete. To see this, consider a queue of depositors at the end of period 1. It is obvious that impatient depositors who enjoy consumption only in period 1 will first join the queue and will never lie about their type. That is, they genuinely join the queue to withdraw their deposits. A patient depositor, however, who has already revealed his type in a noncommittal manner, will first observe the length of the queue before deciding whether to change his mind and join the queue. Thus, a patient queuing depositor is always aware that all depositors behind him are patient. Therefore, a patient depositor will never stay in a queue. If he is the last queuing depositor, he will immediately leave the queue; because if he were to stay in the queue and discover (as he should) that he is last, he will realise that he is better off leaving the queue. If he stays in the queue he will have to accept whatever liquidity is left in the bank, but if he waits until the end of period 2 he is assured to get this quantity of liquidity and probably more. Since this applies to every patient depositor who is last in the queue, and since no impatient depositors queue between two patient depositors, by induction, no patient depositor will stay in a queue at the end of period 1. This implies that the 'cheap talk' messages 
communicated to the bank at the beginning of period 1 must be self-committing, and lying for strategic advantage is impossible. Being aware of this, the bank takes the depositors' messages at the beginning of period 1 as credible and acts as a central planner under aggregate full certainty.

The bank acts as a central planner with similar constrained maximization objective in both cases, under a continuum of depositors and under a discrete number of depositors. In the case of a continuum of depositors a bank run is imminent and the banking system is chronically under a threat of collapse. This is because everyone regards other depositors' messages as incredible and therefore does not consider them of any strategic value. In the case of a discrete number of depositors, messages are credible and therefore are taken fully into strategic consideration. The full certainty depositors enjoy is a direct consequence of their joining the bank. That is, here, unlike DD and GL, the resolution of uncertainty is not at the end of period 1 but rather at the beginning of period 1 when each depositor joins the bank. The returns to depositors are similar to those of DD in the case of a 'good' equilibrium where the bank maximizes welfare of the society of all depositors.

The above discussion leaves open the question of what causes bank runs when the bank, as a central planner, manages the risk sharing of all depositors. It might be claimed that the uncertainty of deposit returns has been overlooked in the above discussion; and that when this is taken into account bank runs may be explained by the uncertainty in future asset prices. Such a claim is invalid because of the following reason. Under such a scenario the most a bank can do is to ensure that asset markets are complete; and a bank run, if it happens, would take the same form as the 'bad' equilibrium in DD with the fundamental difference that the posterior probability of a bank run would be correlated with patient depositor's views of future asset prices. Accordingly, when each depositor informs the bank his type initially in a noncommittal manner, it still guaranties truth telling of all depositors as in the above scenario of no asset price uncertainty.

It may now be concluded that the management of risk sharing by banks is not a cause for bank runs when the management is done in accordance with the strategic behaviour of depositors. The question of what triggers bank run is then left unanswered as is mentioned above. It will be argued in the sequel that the price mechanism in partial equilibrium is consistent with no run on the bank. Therefore bank runs may not be explained in a partial equilibrium analysis as in DD and GL. It will also be argued that when the operations of banks are explained within a general disequilibrium analysis, the price mechanism of adjusting prices according to market forces of excess demands may be a cause that triggers runs on banks.

\section{The price mechanism as a cause for bank runs}

It has long been observed (Allais, 1987) that the investment technology of the bank, as is described above by the returns of schemes 1 and 2, leads to a peculiar balance sheet structure of the bank's assets, where promises to pay back its depositors fall short of its liabilities which are the individuals' deposits that may be withdrawn on demand. This peculiar structure of the bank's balance sheet is the cause for financial fragility (see Abraham, 2009). In this section the asset price mechanism in partial equilibrium and in general disequilibrium will be outlined with a reference to bank runs. It will be explained why the peculiarity of the bank's balance sheet structure is not a cause for bank runs in partial equilibrium, while it may be a cause for bank runs in general disequilibrium.

\section{Partial equilibrium}

Consider a competitive setting in partial equilibrium with the same time profile as above and without banks. At the beginning of period 1 all individuals are uncertain of their type. Therefore each individual would hold a certain amount of his wealth (i.e., endowment) in a liquid asset and the rest in an illiquid asset. At the end of period 1 each individual discovers his type. He then reveals his type, patient or impatient, to the other traders in the market. This setting (due to Allen \& Gale, 1994) is similar to DD with the absence of a bank as a central planner. At the end of period 1 there is an auctioneer who declares prices to settle the asset market in equilibrium. The price clearing kernel in partial equilibrium is $\mathrm{P}=\min \{\mathrm{R}, \mathrm{M} / \mathrm{L}\}, \mathrm{M} / \mathrm{L} \leq \mathrm{R}$, where $\mathrm{M}$ is the total amount of the liquid asset held by the patient individuals and $\mathrm{L}$ is the total amount of the illiquid asset held by the impatient individuals. In the price clearing kernel, $\mathrm{P}=\mathrm{M} / \mathrm{L}$ is the cash-in-the-market price (i.e., liquidity constrained price) and $\mathrm{P}=\mathrm{R}$ is the standard efficient market price. In this partial equilibrium framework the price $\mathrm{P}$ declared by the auctioneer is an equilibrium price.

In the above partial equilibrium framework, the cash-in-themarket equilibrium price can be brought closer to the market efficient price by introducing a bank acting as a central planner and a provider of liquidity. The provision of liquidity by the bank against IOU is a safe operation because the IOU will always be honoured. This observation renders the treatment of bank runs in partial equilibrium problematic. This stands in contradiction to reality where bank runs do occur and sometimes they are even frequent. In the sequel an explanation for bank runs is suggested despite the truth telling strategy of depositors. This is based on the price adjustment mechanism in general disequilibrium.

\section{General disequilibrium}

Now consider a general disequilibrium setting where each individual holds more than one good including fiat money. At disequilibrium prices not all markets clear, therefore prices change according to market forces of excess demands. Thus, if there is positive (negative) market excess demand for a certain good its price rises (falls). In addition, (a) individuals trade with each other in the direction of their excess demands and (b) trade between individuals is conducted such that each individual's value (at current prices) of purchases equals the value of sells. Trade that maintains (a) and (b) complies with price taking behaviour in a competitive environment. It is known (Arrow \& Hahn, 1971:340) that when prices change according to market excess demands and trade takes place at prevailing prices 
according to (a) and (b), in general, some individuals run out of cash (liquidity), the price adjustment mechanism will reach an impasse and general equilibrium prices will fail to exist.

Unlike the partial equilibrium framework, the introduction of banks in general disequilibrium admits episodes of bank runs. Because of the above impasse, in general disequilibrium the bank does not know whether the IOU received against the provision of liquidity will be honoured. While the bank provides liquidity at general disequilibrium, prices change and therefore the individuals who owe the bank IOU might not have sufficient liquidity to honour their obligations. When such a situation arrives patient depositors might reverse their initial strategy and become impatient. This can cause a run on the bank and bankruptcy. Such a possibility, however, is not reflected in the partial equilibrium framework.

\section{References}

Abraham, H. 2009. 'Financial fragility: An assessment', Journal for Studies in Economics and Econometrics, 33:2131.

Abraham, H. 2008. 'Bank runs: A risk mismanagement perspective: A note', South African Journal of Business Management, 39: 63-5.

Allais, M. 1987. 'The credit mechanism and its implications', In Feiwel, G. (ed.) Arrow and the foundations of the theory of the economic policy. New York: New York University Press.

Allen, F. \& Gale, D. 1994. 'Limited market participation and volatility of asset prices', American Economic Review, 84: 933-955.

Arrow, K. J. \& Hahn, F. H. 1971. General competitive analysis. San Fransisco: Holden-Day.

Diamond, D. \& Dybvig, P. 1983. 'Bank runs, deposit insurance, and liquidity', Journal of Political Economy, 91: 401-419.

Farrell, J. \& Rabin, M. 1996. 'Cheap talk', Journal of Economic Perspectives, 10: 103-118.

Green, E. J. \& Lin, P. 2000. 'Diamond and Dybvig's classic theory of financial intermediation: What's missing?', Federal Reserve Bank of Minneapolis Quarterly Review, 24:3-13.

Raiffa, H. 1968. Decision analysis: Introductory lectures on choice under uncertainty. New York: Random House.

Tirole, J. 2006. The theory of corporate finance. Princeton: Princeton University Press. 